\title{
A systematic review of psychotherapy research topics (2000-2016): a computer-assisted approach
}

\author{
Alessandro Gennaro, ${ }^{1}$ Omar C.G. Gelo, ${ }^{2,3}$ Gloria Lagetto, ${ }^{2}$ Sergio Salvatore ${ }^{1}$ \\ ${ }^{1}$ Department of Dynamic and Clinical Psychology, La Sapienza University of Rome, Rome, Italy; ${ }^{2}$ Department of History, Social \\ Society and Human Studies, University of Salento, Lecce, Italy; ${ }^{3}$ Faculty of Psychotherapy Science, Sigmund Freud University, Vienna, \\ Austria
}

\begin{abstract}
The present work aims to empirically map what has been investigated and which issues (i.e. topics) characterize the debates of psychotherapy research, using a computer-assisted, bottom-up method of content analysis. The abstract of papers $(\mathrm{N}=13,499)$, published between 2000-2016 and retrieved from a sample of 10 journals selected as representing the field of psychotherapy research, were subjected to a method of automated content analysis. Five different research topics were identified (clinical relationship, clinical efficacy, clinical practice and research, psychopathology, and neuroscientific approaches to mental disorders) and each abstract was labeled according to the retrieved research topic. Two different Chi-square analyses investigated the distributions of research topics over time and among the selected journals. Results concerning the distribution over time highlighted an increase in the clinical relationship and clinical efficacy topics and a decrease in the others. An examination of the distribution among journals showed that psychopathology and neuroscientific approaches to mental disorders were associated with psychiatric journals, while the others were associated with non-psychiatric journals. The findings are discussed in light of the theoretical, methodological, and practical implications offering pointers for a critical understanding of the current psychotherapy research domain.
\end{abstract}

Key words: Psychotherapy research; Research topic; Literature review; Content analysis.

\section{Introduction}

Psychotherapy research aims at advancing knowledge about psychotherapy by means of scientific methods

Correspondence: Alessandro Gennaro, Department of Dynamic and Clinical Psychology, La Sapienza University of Rome, Via dei Marsi 78, 00158, Rome, Italy.

Tel. +39.3464321376 .

E-mail: a.gennaro@uniroma1.it

Citation: Gennaro, A., Gelo, O. C. G., Lagetto, G., \& Salvatore, S. (2019). A systematic review of psychotherapy research topics (2000-2016): a computer-assisted approach. Research in Psychotherapy: Psychopathology, Process and Outcome, 22(3), 464477. doi: 10.4081/ripppo.2019.429

Conflict of interest: The authors declare no potential conflict of interest.

Funding: None.

Received for publication: 5 September 2019.

Revision received: 7 October 2019.

Accepted for publication: 11 October 2019.

This work is licensed under a Creative Commons Attribution NonCommercial 4.0 License (CC BY-NC 4.0).

${ }^{\circ}$ Copyright: the Author(s), 2019

Licensee PAGEPress, Italy

Research in Psychotherapy:

Psychopathology, Process and Outcome 2019; 22:464-477

doi:10.4081/ripppo.2019.429
(Gelo, Pritz, \& Rieken, 2015). In order to summarize and critically evaluate the body of knowledge produced by this scientific endeavor, literature reviews are used, which are surveys of already published material providing "an indication of the extent to which published scholarship reflects the purpose, interests, and values of a given discipline" (Buboltz, Deemer, \& Hoffmann, 2010; p. 368). Among literature reviews, systematic reviews - where the existing literature is identified and analyzed according to systematic, explicit, and formal criteria - can be considered an elective tool to provide a summary of the knowledge on a particular subject (Grant \& Booth, 2009).

In the field of psychotherapy research, systematic literature reviews deal with the research output, in terms of summary and/or critical evaluation of research results. A prototypical example is meta-analysis, in which quantitative statistical procedures evaluate psychotherapy efficacy/effectiveness (Hofmann, Wu, \& Boettcher, 2014). However, in the field of psychotherapy, systematic literature reviews deal also with the research process itself, thus summarizing and critically evaluating what has been investigated (i.e., the topic of the selected studies: the therapeutic process, therapeutic outcome, relationship between process and outcome, psychotherapy training and/or supervision, etc.) (e.g. Borkenhagen, 2002; Hill \& Knox, 2013; Hill, Nutt, \& Jackson, 1994; Manzo, 2010; Phillips, Ingram, Smith, \& Mindes, 2003; Singh \& Shelton, 2011; Yoon, Langrehr, \& Ong, 2011) and/or how it has been investigated (i.e., the methodology of the se- 
lected studies: research designs, measures employed, etc.; e.g. Borkenhagen, 2002; Buboltz et al., 2010; Gennaro, Venuleo, Auletta, \& Salvatore, 2012; Hill \& Knox, 2013; Hill et al., 1994; Manzo, 2010; Stewart, Stewart, \& Gazda, 1997; Yoon et al., 2011).

The present work represents a systematic literature review trying to answer the question What does psychotherapy research deal with? Specifically, we aim to identify the topics, namely the issues that psychotherapy researchers are interested in, which animate the research debate and characterize the field of psychotherapy research. Different studies have dealt with this issue. Munley (1974), reviewing the Journal of Counseling Psychology (JCP) publications between 1954 and $1972(N=1,400)$, highlighted that the most investigated research topics were counseling process and outcome, vocational behavior, and the development and evaluation of measurement tools and tests; moreover, he observed an increasing trend over time in empirical papers. In a more recent work, Buboltz, Miller, and Williams (1999) reviewed the publications of the JCP in the years 1973-1998 $(N=2,027)$, showing similar results: process and outcome research topics remained relatively stable from 1974 to 1998 , whereas a decreasing trend was found in papers focusing on vocational behavior and psychometric properties of tests and measures. In a further study, Buboltz, Deemer, and Hoffmann (2010) followed up the study of Buboltz et al. (1999) by further analyzing the publications of JCP in the years 1999-2009 $(N=514)$; results showed that the most frequent topics investigated turned toward multiculturalism and/or diversity, development and evaluation of tests and measures, personality and adjustment, outcome research, and interpersonal and/or social support and/or attachment. Moreover, comparing the two studies (Buboltz et al., 1999, 2010), a decrease in process and process-outcome research, and an increase in outcome research and research on multiculturalism and/or diversity could be observed.

Hill, Nutt and Jackson (1994) reviewed studies on psychotherapy published in the JCP and the Journal of Consulting and Clinical Psychology (JCCP) between 1978 and $1992(N=3,145)$. Results showed that most of the publications of JCP dealt with process, outcome, and analogue research, whereas the publications of JCCP mostly with outcome research. Finally, in another work, Stewart et al. (1997) examined the published articles in 23 journals dealing with group psychology and group psychotherapy between 1980 and $1995(N=9,391)$. Results showed that the journals in question published more than half of the papers identified mostly on group psychotherapy, followed by papers on group dynamics and on group counselling. It was also possible to observe that the amount of publications on group dynamics was the most consistent over the 16-year interval considered, while a decline was observed for group counselling and group psychotherapy from 1990 to 1994.

\section{Research topics and systematic literature reviews: overcoming actual methodological limitations}

Systematically reviewing the publication topics in the field of psychotherapy research provides many insights regarding the scope of the discipline and its possible evolution as it is represented in journal publications, with obvious theoretical (e.g., what is the current subject of psychotherapy research?) as well as practical (e.g. where should scholars submit their papers?) implications. However, several limitations could be identified in the works cited above due mainly to the methodology used. First, the content analysis carried out in the existing literature reviews follows a top-down approach (see Mörtl \& Gelo, 2015): It makes use of a coding scheme defined a-priori by the author(s), with consequent limitations on the explorative nature of literature reviews. Indeed, such an approach reflects the research topics that researchers assume are worth identifying, rather than actually mapping the possible topics emerging by considering the published literature. Second, in existing literature reviews on the topics of psychotherapy and counseling research, the content analysis of the identified literature is carried out by human raters, and is therefore tremendously energy- and time-consuming. A possible implication is that this might limit the amount of papers to be included in a review, and consequently the external validity of the results.

In order to overcome these limitations, Gennaro et al. (2012) recently conducted an extensive review on the publications of 17 journals in the period 2005-2011 $(N=7,086)$. The authors employed an innovative procedure of computer-assisted, bottom-up content analysis: the Automated Co-occurrence Analysis for Semantic Mapping (ACASM) (Salvatore et al., 2017; Salvatore, Gennaro, Auletta, Tonti, \& Nitti, 2012). Most of the existing computerized content analytic methods used in the field of psychotherapy research follow a top-down approach based on pre-defined dictionaries: the content categories to be investigated are defined a-priori by the researcher; with each content category represented by a so-called dictionary containing all the words considered to be representative of that category; finally, the software searches the text-corpus and displays the frequency of how many times each category has been counted (e.g. Bucci \& Maskit, 2006; Mergenthaler, 1996; Tausczik \& Pennebaker, 2010). By contrast, ACASM follows a bottom-up approach based on the co-occurrence of lexical items. The researcher selects a dictionary containing the lexical forms characteristic of a specific language; he/she further defines the length of the text unit of analysis (which may vary from one single word to one or more sentences); the software runs a cluster analysis in order to identifies groups (i.e., clusters) of lexical items which tend to co-occur over the units of analysis (with each cluster representing a content identified in the analyzed text-corpus); finally, the researcher produces an interpretation of 
the cluster by providing a name indicating the topic it represents. Thus, the content categories are not defined prior to the analysis, but emerge as a result of it.

In their study to identify the psychotherapy research topics, Gennaro et al. (2012), focused their analysis on the articles' keywords; thus, each cluster identified by ACASM represented a group of keywords which tended to co-occur, and was interpreted as a topic emerging from within the literature under consideration. Results showed four clusters, dealing with the following topics: cognitive and behavior treatment, the study of mental disease, intervention on severe mental disorders, and outcome research, methodology, and results.

\section{Research aims}

In line with the work of Gennaro et al. (2012), the present paper aims to empirically map the topics characterizing the current state of psychotherapy research. As in Gennaro et al. (2012), we make use of a computer-assisted bottom-up content analysis (i.e., ACASM; Salvatore et al., 2012, 2017), with the difference, however, that this will be applied to publications' abstracts rather than keywords. The idea is that papers' abstracts could be more indicative and informative about their actual topic than keywords. As a matter of fact, keywords offer a meaningful initial but still rather generic, superficial clue to a paper's thematic content, whereas abstracts are a more reliable indicator of an article's thematic content, thus proving more helpful in forming a global picture of the psychotherapy research topics (Blake \& Bly, 1993). Reading abstracts is acknowledged as a widespread and time saving way to identify the content of scientific production and it can represent a very useful source of information when, as here, it is used to form a global picture of the research topics in the whole literature. However, we are aware of warnings about the limitations of abstracts, as for example that sometimes research results are not accurately reported or over-interpreted (Pitkin \& Branagan, 1998; Yavchitz et al., 2012), or that the information provided could be incomplete compared with the content of the full publication (Hopewell, 2008).

Moreover, the present work will also focus on the temporal trend research topics might present, since this could offer precious information in order to detect the evolution of psychotherapy research with regard to its topics. Finally, the journals' thematic orientation (i.e., the research topic distribution among the different journals) will be analyzed in order to offer insights regarding the different contents of scientific production in the field of psychotherapy research in different journals, as well as to provide an orientation for scholars when deciding where to submit their work.

In summary, the present study's aims are: i) to identify the research topics characterizing psychotherapy research; ii) to track their trend over time; iii) and to analyze their distribution among different journals.

\section{Methods}

\section{Sample}

A sample of 10 journals was selected as representative of the field of psychotherapy research. Journals were selected in accordance with the following procedure. First, the past presidents (from 1970 to 2013) of the Society for Psychotherapy Research were contacted by mail and asked to provide a ranked list of what they considered to be the 5 most representative journals in the field of psychotherapy research. The responding past presidents ( 24 out 35 contacted) answered our request indicating an overall number of 25 different journals (see Acknowledgements). Second, each rank was assigned to a representativeness score ( $1^{\text {st }}$ rank $=1.00 ; 2^{\text {nd }}$ rank $=0.8 ; 3^{\text {th }}$ rank $=0.6 ; 4^{\text {th }}=0.4 ; 5^{\text {th }}$ rank $=0.2$ ), then the 10 journals presenting the highest representativeness score were chosen as the base to retrieve the articles examined in our systematic review. Finally, we selected all the original contributions (theoretical and empirical studies) from each of the selected journals published from 2000-2016.

We considered this period wide enough to provide a reliable picture of the actual topics characterizing the current state of the field. From the $(\mathrm{N}=18,819)$ records collected, $\mathrm{N}=5,320$ records - consisting of commentaries, introduction to special issues and to special sections, editorials, presidential addresses, acknowledgments, book and video reviews, book forums, letters to the editor, indexes, errata, and obituaries - were not included in our sample because they do not meet the inclusion criteria (they were considered not to provide any original research contribution). In the event of discrepancies between judges, the articles were revised through discussions in order to reach consensus on coding. As a result of this sampling procedure, a total of $N=13,499$ full-text articles were assessed for eligibility and were collected using Summon database. Subsequently, the abstracts of each article were extracted, and subjected to data analysis (see Figure 1 - based on the PRISMA Group: Moher, Liberati, Tetzlaff, \& Altman, 2009 - and Table 1).

\section{Data analysis}

\section{Automated Co-occurrence Analysis for Semantic Mapping method}

In order to identify the topics (i.e., thematic content) characterizing the field of psychotherapy research (research question 1), the ACASM was applied (Salvatore et al., 2012, 2017). ACASM is a bottom-up, context-sensitive automated method of textual analysis, aimed at supporting interpretation of textual data. The choice to adopt such a text analytic method for data analysis is due to its reliability in retrieving thematic contents and to its low inferential and time saving characteristics (Salvatore et al., 2012, 2017). A first study highlighted that ACASM's ability to categorize the semantic contents (i.e., topics) of 
good outcome experiential psychotherapy transcripts was functionally equivalent to the semantic analysis carried out by human raters on the same session transcripts (Salvatore et al., 2012). Furthermore, Salvatore et al. showed that the case interpretation provided by clinicians relying on the ACASM analysis of a good outcome psychodynamic psychotherapy was as reliable as the case interpretation provided by clinicians relying on the verbatim transcripts of the same sessions.

ACASM is a bottom-up procedure of text analysis based on explicit, invariant rules of coding and yet able to take the contextuality of meaning into account (Salvatore et al., 2012, p. 258; italic added). ACASM is aimed at extrapolating thematic contents (i.e., semantic meanings) active in the text. Each thematic content is characterized by a cluster of words which tend to co-occur (i.e., to be associated with each other) throughout the text (Lancia, 2004). Such sets of co-occurring words are identified by means of invariant but context-sensitive computational rules automatically implemented by an $a d-h o c$ software. ACASM is a specimen of a broader class of methods for computer-assisted semantic analysis focusing on the cooccurrence of lexical units (e.g., ALCESTE, Reinert, 1993; Latent Semantic Analysis, Chung \& Pennebaker, 2008; Landauer \& Dumais, 1997; Meaning Extraction Method, Max, 1993; Wolf, Chung, \& Kordy, 2010).The main specificity of ACASM is that it adopts a single sentence or a group of a few sentences as its unit of context (the unit of context is the segment of text within which co-occurrences are detected).

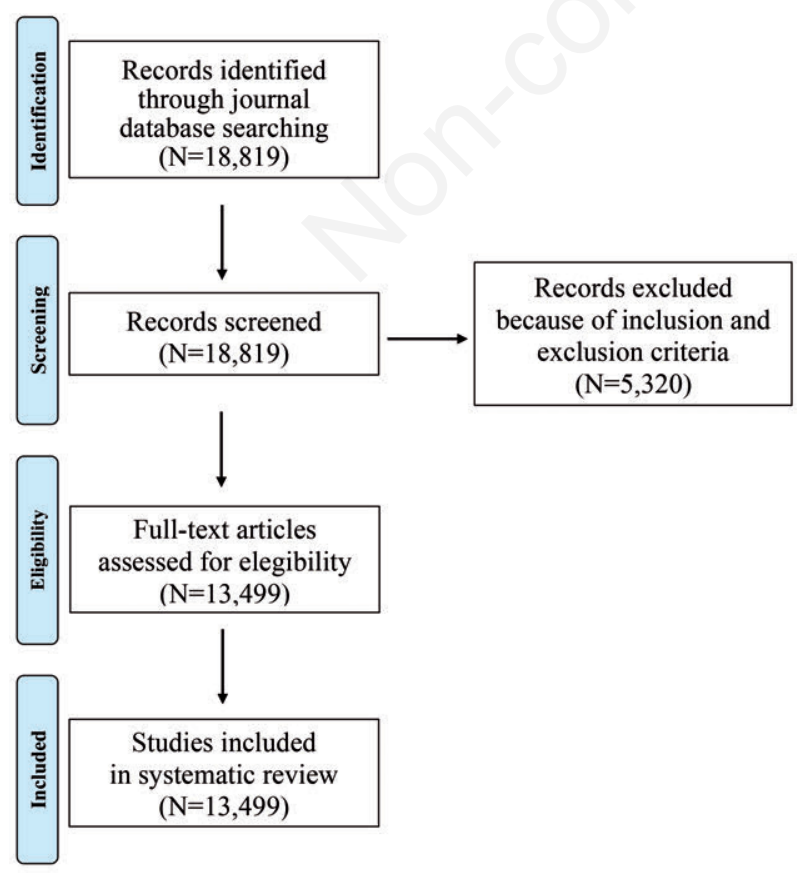

Figure 1. Flow diagram of study selection (the figure has been created according to PRISMA group indications).

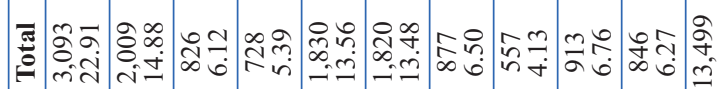

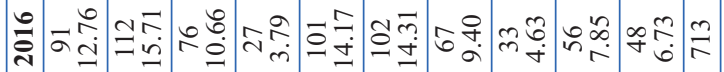

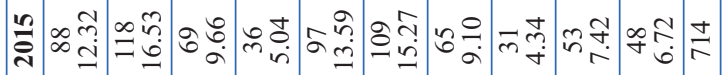

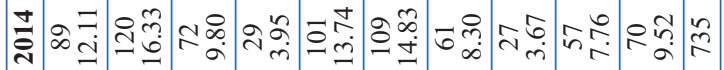

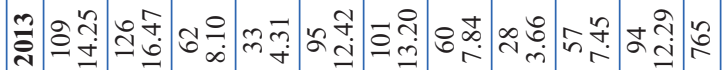

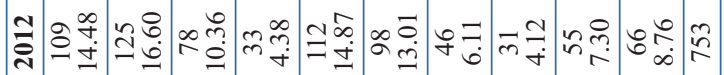

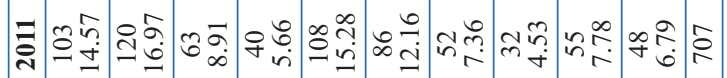

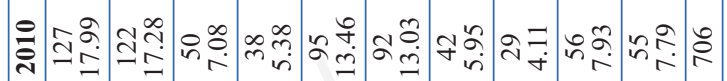

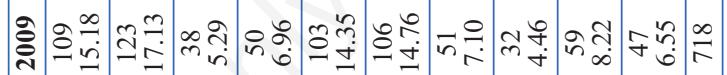

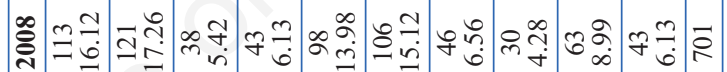

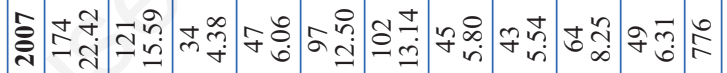

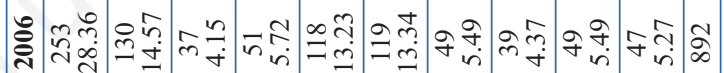

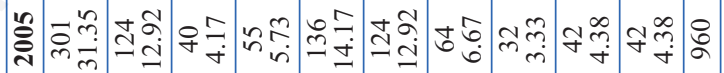

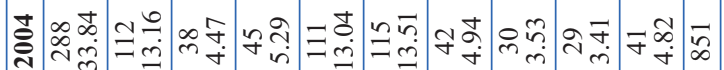

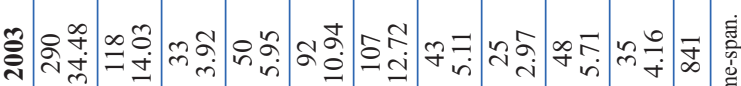

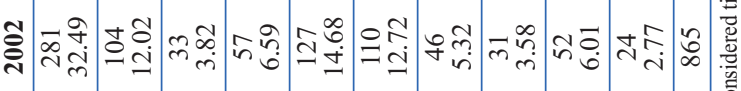

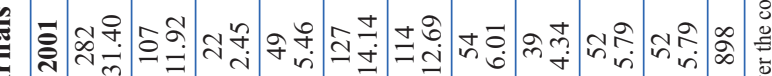

要

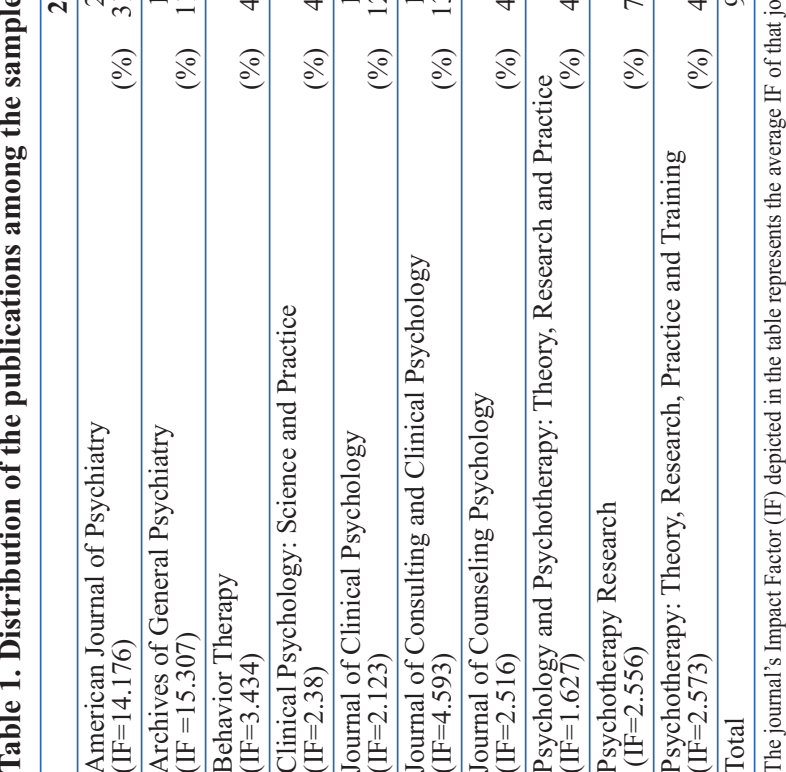




\section{Procedure}

Retrieved abstracts were firstly subjected to ACASM analysis. To this end, the following operations were performed (see Salvatore et al., 2010 for more details on the procedure). Elementary Context Units were identified (ECUs) according to the following criteria: i) Each ECU begins just after the end of the previous ECU; ii) each ECU ends after the first punctuation mark (', , or '!', or '?') occurring after the threshold of 2000 characters from the first character; iii) if an ECU is longer than 2000 characters, it ends with the last word found within such a length, even if there is no punctuation mark. According to such threshold, each abstract corresponded to an ECU. Then, a dictionary for the text-analysis was constructed. In order to do this, each lexical form present in the abstracts under analysis were categorized into the lemma it belongs to. This produced a list of lemmas present in the analyzed textual corpus. In order to exclude the highly frequent lemmas, the first 5\% were excluded; this was done since very high-frequency lemmas (such as to, and, of, etc.) tend to co-occur in too many different ECUs, reducing their ability to discriminate among different patterns of co-occurrence. In so doing we obtained a list corresponding to 980 lemmas.

The textual corpus was digitally represented in terms of a matrix displaying the ECUs (i.e., each abstract) in rows and lemmas in columns; the cell $\mathrm{x}_{\mathrm{ij}}$ received the value ' 1 ' if the $j_{\text {th }}$ lemma was contained in the $\mathrm{i}_{\mathrm{th}} \mathrm{ECU}$, the value ' 0 ' otherwise. A cluster analysis (Aldenderfer \& Blashfield, 1984) was applied to the matrix in order to group the ECUs into clusters, using the co-occurrence of lemmas among the ECUs as criterion of similarity - in this way, each cluster could be considered a thematic content active in the textual corpus, since it contained abstracts sharing a similar pattern of co-occurring lemmas, therefore a semantic content. The number of clusters in which the text is segmented was established using an iterative algorithm; the procedure of clustering stops when further partitions produce no further significant improvement of the inter/intra cluster ratio, which means that increasing the number of clusters does not produce an appreciable increment of information (this procedure is analogous to the saturation process in bottom-up qualitative analyses, through which informational redundancy is reached; Mörtl \& Gelo, 2015). Finally, each of these clusters was labeled through a consensus-reaching procedure by three judges experienced in text analysis, supervised at regular intervals by an auditor (Hill et al., 2005).

Once the research topics had been identified through the ACASM method, a set of chi-square analyses were carried out in order to investigate respectively the distributions of research topics over time according to three major time periods: 2000-2005, 2006-2010, and 2011-2016 (research question 2), and on the other hand the distribution of topics retrieved in the selected journal over time (research question 3). For a more accurate reading, adjusted standard residuals were retrieved. Adjusted standard residuals are normally dis- tributed, thus cells having absolute values greater than the critical value $N(0,1) 1-\alpha / 2=1.96$ will have raw $\mathrm{p}$-values of less than 0.05 (for a two-sided test). In so doing post-hoc hypotheses tests on standardized residuals were tested.

\section{Results}

\section{Research topics}

In accordance with the ACASM method, the cluster analysis was run on the data matrix having as rows the 13,499 abstracts and 980 lemmas as columns; each $i j$-th cell reported the relative frequency of the $j$-th lemma in the $i$-th abstract. cluster analysis led to group keywords in sets of maximum inner homogeneity and maximum outer divergence. This procedure allowed us to retrieve 5 clusters as optimal partition. Each cluster is interpreted as identifying one specific topic, since it is depicted by a particular aggregation of co-occurring lemmas (Table 2).

\section{Cluster 1: Clinical relationship}

This cluster represents $21.26 \%$ of the abstracts analyzed. This cluster groups research works dealing with the clinical relationship in terms of development, comparison of specific variables among groups and treatments, and outcome predictions and/or associations.

\section{Cluster 2: Clinical efficacy}

The $20.82 \%$ of the abstracts analyzed are grouped in this cluster. The cluster accounts for studies and research work testing the ability of psychotherapeutic treatments to achieve the intended outcome by means of randomized clinical trials (RCTs).

\section{Cluster 3: Clinical practice and research}

In this cluster, we found $19.52 \%$ of the papers analyzed. It considers papers dealing with professional practice and training, and research-practice bridging.

\section{Cluster 4: Psychopathology}

This cluster represents $19.43 \%$ of the abstracts analyzed. The studies grouped in this cluster concern disorder assessment and identification of risk behaviors both in inpatient and outpatient settings.

\section{Cluster 5: Neuroscientific approaches to mental disorders}

This cluster represents $18.97 \%$ of the abstracts under analysis. This cluster covers studies dealing with neurological or neurobiological factors, abnormalities of specific cortical areas intervening in psychiatric and psychological impairments.

\section{Research topics over time}

The first set of chi-square-analyses highlighted meaningful differences concerning the distribution of clusters 


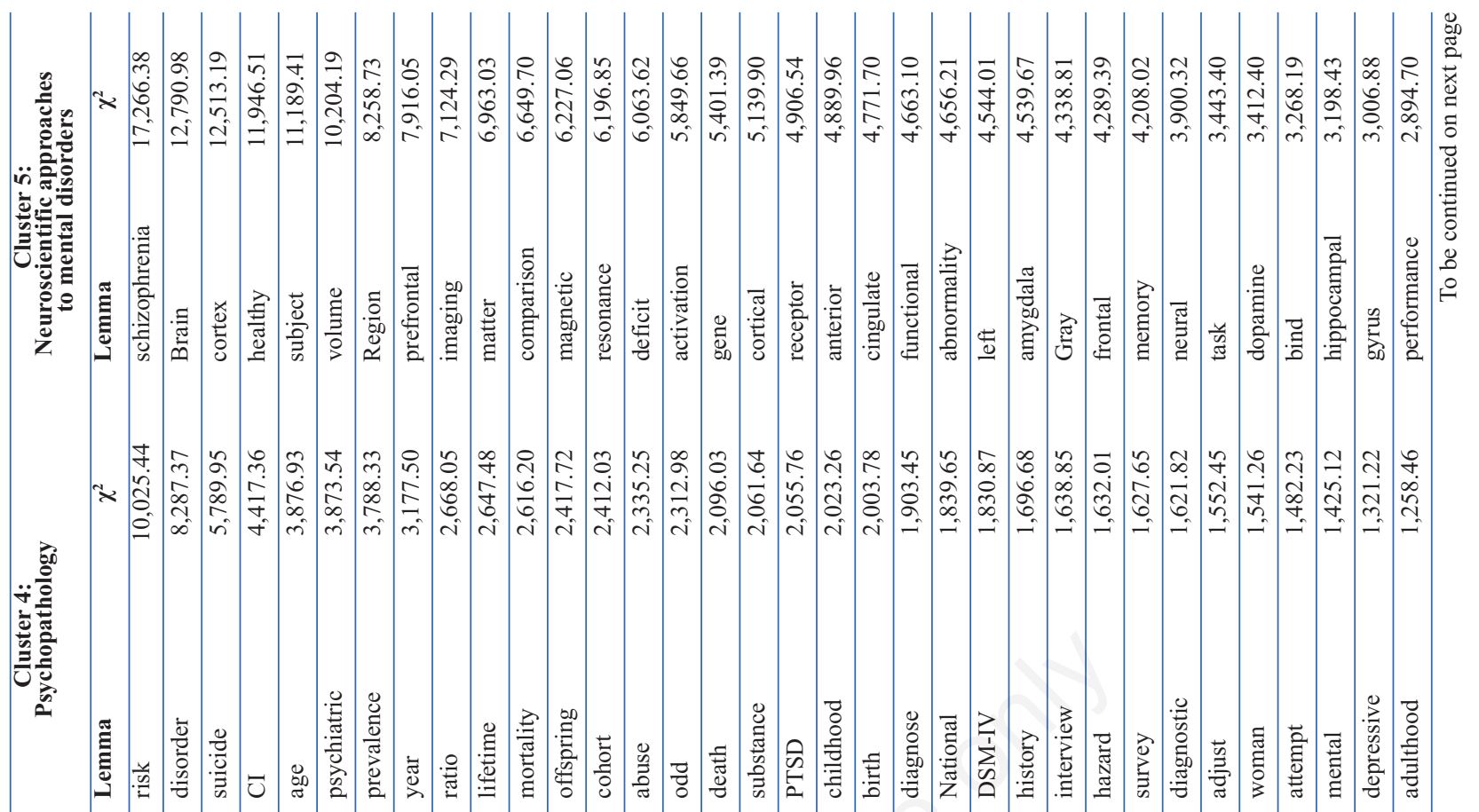

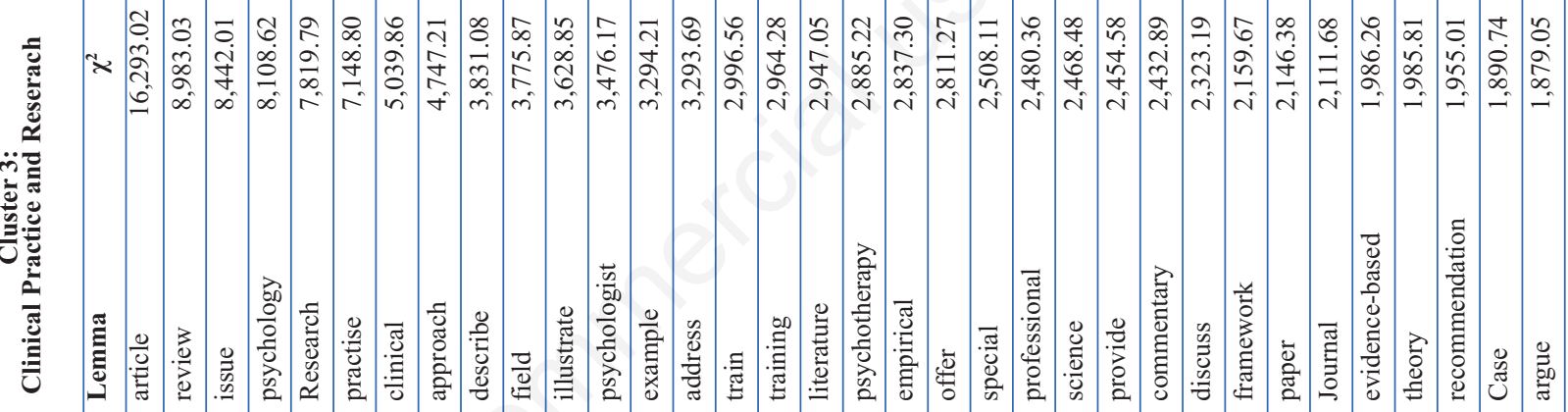

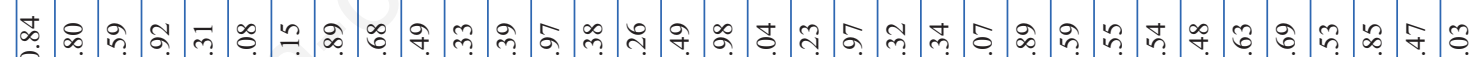

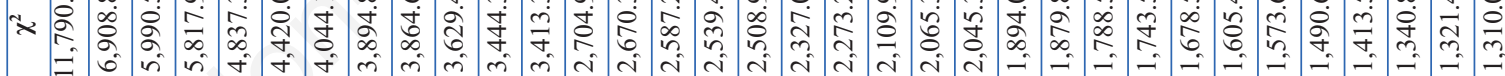
政 . 


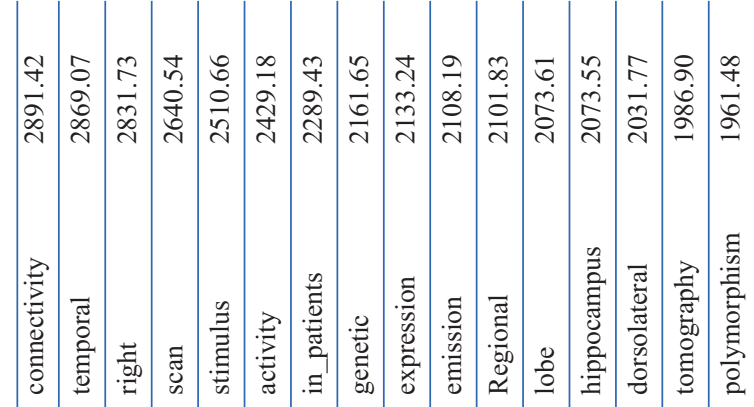

을

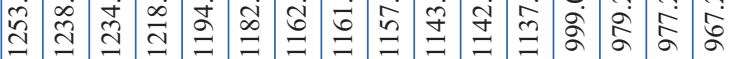

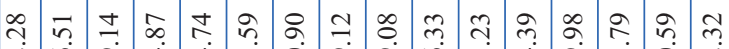
तิ

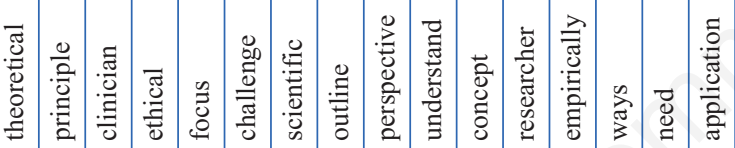

m

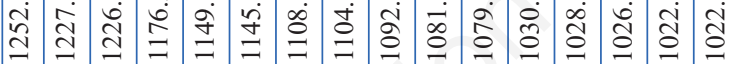

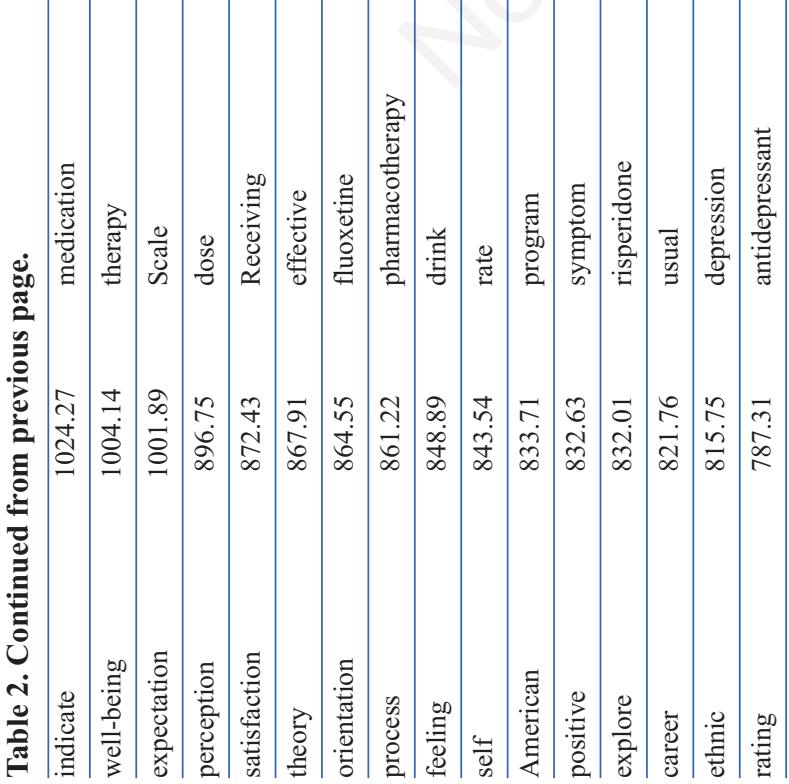

identified (i.e. research topics) over time $\left(\chi^{2}=199.26 ; d f=8\right.$; $p .=.000$ ). The adjusted residuals' analysis (Table 3 ) reveals a slightly decreasing trend in research work dealing with neuroscientific approaches to mental disorders (cluster 5), clinical practice and research (cluster 3), and psychopathology (cluster 4), while there is an increasing trend in clinical relationship (cluster 1) and clinical efficacy studies (cluster 2).

\section{Research topics among journals}

A second set of chi-square analyses highlighted the distribution of each research clusters (i.e. research topics) among the different journals (Table 4). The chi-square test proved significant $\left(\chi^{2}=12740.06 ; d f=36 ; p .=.000\right)$. It was possible to identify differences concerning the distribution of articles published in the different journals (Table 4). Specifically, the topic clinical relationship presents higher occurrences in five out of ten journals: Journal of Counseling Psychology (Adj. res=39.9) and Psychotherapy Research (Adj. res=38.1), followed by Psychology and Psychotherapy (Adj. res=15.9) and by Psychotherapy: Theory, Research, Practice and Training (Adj. res=8.5) and Behavior Therapy (Adj. res=6.2). The topic of clinical efficacy presents higher prevalence in the Journal of Consulting and Clinical Psychology (Adj. res=36.1), followed by Behavior Therapy (Adj. res=10.5). The topics of neuroscientific approaches to mental disorders and psychopathology present a high prevalence in the American Journal of Psychiatry (Adj. res=42.3 and 17.4, respectively) and in the Archives of General Psychiatry (Adj. res $=32$ and 25.4, respectively). Finally, the clinical practice and research topic is prevalent in Clinical Psychology: Science and Practice (Adj. res=42.7), Journal of Clinical Psychology (Adj. res=30.8), and in Psychotherapy: Theory, Research, Practice and Training (Adj. res=27.7).

\section{Discussion}

The present paper aimed at providing a systematic review of the research topics in the field of psychotherapy by means of a computer-assisted, bottom-up content analysis, as well as their distribution over time and among sources of publication.

\section{Research topics}

With regard of our first research aim, it was possible to identify five research topics: clinical relationship, clinical efficacy, clinical practice and research, psychopathology, and neuroscientific approaches to mental disorders. Each research topic covered about one in five of the overall scientific production, thus testifying that the scientific production in the field is quite equally distributed among these topics. The research topics identified seem to have a good face validity insofar as they refer to 
constructs which most scholars would acknowledge as relevant in the field of psychotherapy research.

Consider the research topic of clinical efficacy - the second most frequent in our sample - which deals with the investigation of the effects of psychotherapeutic techniques/methods in highly controlled experimental settings
(Lambert, 2013b; Leichsenring, 2004). Clinical efficacy has been a major interest since the birth of modern psychotherapy research, back in the ' $50 \mathrm{~s}$, in response to Eysenck's attack on the effects of psychotherapy (according to which clients' recovery simply reflected spontaneous remission (Braakmann, 2015; Eysenck, 1952).

Table 3. Chi-square test's residuals about the distribution of research topic over time.

\begin{tabular}{|c|c|c|c|c|c|}
\hline \multirow[t]{2}{*}{ Cluster } & & \multicolumn{3}{|c|}{ Time Span } & \multirow[b]{2}{*}{ Total } \\
\hline & & $2000-2005$ & 2006-2010 & 2011-2016 & \\
\hline \multirow[t]{2}{*}{ Clinical Relationship } & Count & 1010 & 958 & 1152 & 3120 \\
\hline & Adj. Res & -9.2 & 3.7 & 6 & \\
\hline \multirow[t]{2}{*}{ Clinical Efficay } & Count & 984 & 765 & 1058 & 2807 \\
\hline & Adj. Res & -5.3 & -1.1 & 6.6 & \\
\hline \multirow[t]{2}{*}{ Clinical Practice and Reserach } & Count & 1161 & 782 & 867 & 2810 \\
\hline & Adj. Res & 2.3 & -0.4 & -2.1 & \\
\hline \multirow[t]{2}{*}{ Psychopathology } & Count & 1097 & 681 & 732 & 2510 \\
\hline & Adj. Res & 4.9 & -1.2 & -4 & \\
\hline \multirow[t]{2}{*}{ Neuroscientific approaches to mental disorders } & Count & 1067 & 607 & 578 & 2252 \\
\hline & Adj. Res & 8.5 & -1.3 & -7.6 & \\
\hline Total & & 5319 & 3793 & 4387 & 13499 \\
\hline
\end{tabular}

Adj. Res., Adjusted Standard Residual ( $\mathrm{P}<.05$ for Adj.Res. $>1.96)$.

Table 4. Chi-square test's residuals about the distribution of research topics among journals.

\begin{tabular}{|c|c|c|c|c|c|c|c|}
\hline Journal & & & & Cluster & & & \\
\hline & & $\begin{array}{c}\text { Clinical } \\
\text { Relationship }\end{array}$ & $\begin{array}{l}\text { Clinical } \\
\text { Efficacy }\end{array}$ & $\begin{array}{c}\text { Clinical } \\
\text { Practice and } \\
\text { Research }\end{array}$ & Psychopathology & $\begin{array}{l}\text { yeuroscientific } \\
\text { approaches to } \\
\text { mental disorders }\end{array}$ & Total \\
\hline $\begin{array}{l}\text { American Journal } \\
\text { of Psychiatry }\end{array}$ & $\begin{array}{c}\text { Count } \\
\text { Adj. Res. }\end{array}$ & $\begin{array}{c}43 \\
-32.6\end{array}$ & $\begin{array}{l}685 \\
2.1\end{array}$ & $\begin{array}{c}173 \\
-23.8\end{array}$ & $\begin{array}{l}906 \\
17.4\end{array}$ & $\begin{array}{l}1286 \\
42.3\end{array}$ & 3093 \\
\hline $\begin{array}{l}\text { Archives of General } \\
\text { Psychiatry }\end{array}$ & $\begin{array}{l}\text { Count } \\
\text { Adj. Res. }\end{array}$ & $\begin{array}{c}8 \\
-26.2\end{array}$ & $\begin{array}{l}352 \\
-3.9\end{array}$ & $\begin{array}{c}39 \\
-22.6\end{array}$ & $\begin{array}{l}782 \\
25.4\end{array}$ & $\begin{array}{c}828 \\
32\end{array}$ & 2009 \\
\hline Behavior Therapy & $\begin{array}{c}\text { Count } \\
\text { Adj. Res. }\end{array}$ & $\begin{array}{l}264 \\
6.2 \\
\end{array}$ & $\begin{array}{l}290 \\
10.5\end{array}$ & $\begin{array}{r}150 \\
-1.9\end{array}$ & $\begin{array}{c}76 \\
-7.2\end{array}$ & $\begin{array}{c}46 \\
-8.8\end{array}$ & 826 \\
\hline $\begin{array}{l}\text { Clinical Psychology: } \\
\text { Science and Practice }\end{array}$ & $\begin{array}{l}\text { Count } \\
\text { Adj. Res. }\end{array}$ & $\begin{array}{c}52 \\
-10.5\end{array}$ & $\begin{array}{c}34 \\
-11\end{array}$ & $\begin{array}{l}607 \\
42.7\end{array}$ & $\begin{array}{c}25 \\
-10.8\end{array}$ & $\begin{array}{c}10 \\
-11.4\end{array}$ & 728 \\
\hline $\begin{array}{l}\text { Journal of Clinical } \\
\text { Psychology }\end{array}$ & $\begin{array}{c}\text { Count } \\
\text { Adj. Res. }\end{array}$ & $\begin{array}{l}436 \\
0.8\end{array}$ & $\begin{array}{l}227 \\
-9.5\end{array}$ & $\begin{array}{r}879 \\
30.8\end{array}$ & $\begin{array}{l}244 \\
-6.2\end{array}$ & $\begin{array}{c}44 \\
-17.6\end{array}$ & 1830 \\
\hline $\begin{array}{l}\text { Journal of Consulting and } \\
\text { Clinical Psychology }\end{array}$ & $\begin{array}{l}\text { Count } \\
\text { Adj. Res. }\end{array}$ & $\begin{array}{l}374 \\
-2.8\end{array}$ & $\begin{array}{r}960 \\
36.1\end{array}$ & $\begin{array}{c}125 \\
-15.8\end{array}$ & $\begin{array}{l}344 \\
0.4\end{array}$ & $\begin{array}{c}17 \\
-19.4\end{array}$ & 1820 \\
\hline $\begin{array}{l}\text { Journal of Counseling } \\
\text { Psychology }\end{array}$ & $\begin{array}{c}\text { Count } \\
\text { Adj. Res. }\end{array}$ & $\begin{array}{l}684 \\
39.9\end{array}$ & $\begin{array}{c}42 \\
-12.1\end{array}$ & $\begin{array}{c}88 \\
-8.1\end{array}$ & $\begin{array}{c}62 \\
-9.1\end{array}$ & $\begin{array}{c}1 \\
-13.6\end{array}$ & 877 \\
\hline $\begin{array}{l}\text { Psychology and } \\
\text { Psychotherapy }\end{array}$ & $\begin{array}{l}\text { Count } \\
\text { Adj. Res. }\end{array}$ & $\begin{array}{l}284 \\
15.9\end{array}$ & $\begin{array}{c}71 \\
-4.8\end{array}$ & $\begin{array}{l}131 \\
1.6\end{array}$ & $\begin{array}{c}56 \\
-5.3\end{array}$ & $\begin{array}{l}15 \\
-9\end{array}$ & 557 \\
\hline Psychotherapy Research & $\begin{array}{l}\text { Count } \\
\text { Adj. Res. }\end{array}$ & $\begin{array}{r}679 \\
38.1\end{array}$ & $\begin{array}{c}93 \\
-8.2\end{array}$ & $\begin{array}{r}125 \\
-5.5\end{array}$ & $\begin{array}{c}12 \\
-13.9\end{array}$ & $\begin{array}{c}4 \\
-13.6 \\
\end{array}$ & 913 \\
\hline $\begin{array}{l}\text { Psychotherapy: Theory, } \\
\text { Research, Practice and Training }\end{array}$ & $\begin{array}{l}\text { Count } \\
\text { Adj. Res. }\end{array}$ & $\begin{array}{l}296 \\
8.5\end{array}$ & $\begin{array}{c}53 \\
-10.8\end{array}$ & $\begin{array}{l}493 \\
27.7\end{array}$ & $\begin{array}{c}3 \\
-14.1\end{array}$ & $\begin{array}{c}1 \\
-13.3\end{array}$ & 846 \\
\hline Total & Count & 3120 & 2807 & 2810 & 2510 & 2252 & 13499 \\
\hline
\end{tabular}

Adj. Res., Adjusted Standard Residual ( $\mathrm{P}<.05$ for Adj.Res. $>1.96)$. 
Eysenck's attack had a tremendous catalyst effect on the application and further development of quantitative methods for the investigation of psychotherapy outcome which has led, nowadays, to the implementation of RCTs. The latter, to date, are considered the gold standard to produce the best research evidence for demonstrating that a therapy works, as reflected in the criteria of the Task Force of the American Psychological Association (APA) Division 12 (Clinical Psychology) for empirically supported treatments (ESTs; Chambless \& Hollon, 1998), within the more general framework of the evidence-based practice (EBP) movement (American Psychological Association, Presidential Task Force on Evidence-Based Practice, 2006). Our results show that an EBP-based, EST-oriented approach to the investigation of therapeutic efficacy is (still) a primary concern for current psychotherapy research (Gennaro et al., 2012; Gelo et al., 2019).

Another topic which emerged very clearly in the field of psychotherapy research is the clinical relationship, which addresses the ongoing therapeutic relationship between client and therapist during the treatment. Research on the therapeutic relationship began in the " $60 \mathrm{~s}$ with Rogers and his research group, but it has witnessed a huge growth only starting from the ' 80 s, as a result of the metaanalytic findings suggesting the therapeutic equivalence of different therapeutic approaches (Braakmann, 2015; Wampold \& Imel, 2015). Since then, in the attempt to identify therapeutic factors which are common to the different orientations - the so called common therapeutic factors (McAleavey \& Castonguay, 2015; Wampold \& Imel, 2015), researchers have increasingly turned their attention to the role of the therapeutic relationship (Budge \& Wampold, 2015) and of other constructs strictly related to it, such as the therapeutic alliance (Flückiger, Del Re, Wampold, Symonds, \& Horvath, 2012) and attachment (Daniel, 2006), especially with the aim of identifying client and therapist related factors contributing to these phenomena. This increasing interest has been manifested to such an extent that it might be possible to talk of an interpersonal turn in psychotherapy research (Lingiardi, Holmqvist, \& Safran, 2016; Wachtel, 2008; for a critical discussion, see Slife \& Wiggins, 2009). Moreover, this interest is today testified by the joint effort of the APA Division 29 (Psychotherapy) and Division 12 (Clinical Psychology) which, as a reaction to some of the perceived limitations of the ESTs, established a Task Force to disseminate information on empirically supported relationships (ESRs; Kazantzis, Cronin, Norton, Lai, \& Hofmann, 2015; Norcross, 2011). Within the more general aim of offering an additional framework for integrating the best research evidence with clinical expertise coherent with the EBP movement (American Psychological Association, Presidential Task Force on Evidence-Based Practice, 2006), this Task Force intended to identify i) the "effective elements of the psychotherapy relationship" (What works in general in the therapy relationship?) and ii) the "effective methods of adapting or tailoring therapy to the individual patient" (What works best for particular patients?) (Norcross, 2011; p.vii). Our results indicate that current psychotherapy research, in the attempt to further understand why therapy works, with whom, and under which conditions (Roth \& Fonagy, 2005) within the context of EBP, has now moved beyond the main interest in the technical aspects of a treatment, embracing also the role that relational factors may have in psychotherapeutic change.

The third research topic was clinical practice and research, which is comprised mainly - though not exclusively - of theoretical-methodological papers and narrative reviews dealing with different aspects of professional practice and training on one hand, and of researchpractice bridging on the other. Concerning the first aspect, the identification of such a research topic actually testifies the increasing interest that the psychotherapy research landscape has come to show with regard to aspects regarding professional development and training. Such an interest in the field is attested, for example, by the inclusion, for the first time, of an empirical review on training and supervision in the last edition of Bergin and Garfield's handbook of Psychotherapy and Behavior Change (Hill $\&$ Knox, 2013). Another example is the establishment of an interest section on therapist training and development in the Society for Psychotherapy Research (SPRISTAD; e.g. Rønnestad, Orlinsky, Schröder, Skovholt, \& Willutzki, 2018). Regarding the second aspect, our results testify to the interest shown by current psychotherapy research in describing the so-called science-practice gap and in trying to identify ways to address it (Boisvert \& Faust, 2006; Gaudiano \& Miller, 2013; Lilienfeld, Ritschel, Lynn, Cautin, \& Latzman, 2013; Newnham \& Page, 2010; Safran, Abreu, Ogilvie, \& DeMaria, 2011). The science-practice gap is related to the extent of integration between psychotherapeutic science and psychotherapeutic practice, and can be described as the gap existing between "the output generated by research protocols, such as treatment manuals, and the use of such output by clinicians in the trenches of clinical work" (Lilienfeld et al., 2013; p. 894). Actually, the development of the EBP movement mentioned above - both with regard to ESTs and ESRs - can be considered one of the main attempts to promote such a scientist-practitioner integration, in order to bridge this gap. In fact, EBP can be defined as comprising "the thoughtful integration of the best available scientific evidence concerning psychotherapy with clinical expertise and client preferences/values" (Lilienfeld et al., 2013; p. 886). However, notwithstanding this attempt, a controversy actually exists regarding the extent to which the current EBP approach can effectively reduce the science-practice gap. Apart from the many possible causes responsible for such a gap (Lilienfeld et al., 2013), the heart of the controversy seems to revolve around the question of best-research evidence, that is, 
what qualifies as evidence (Stiles et al., 2006; Stewart, Stirman, \& Chambless, 2012; for a critical discussion, see Slife, Wiggins, \& Graham, 2005).Coherently with this observation, a practice-based evidence approach has been proposed, which represents a shift in how we think about evidence, complementing rather than replacing the research that informs the evidence-based practice guidelines (Green \& Latchford, 2012, p. 87). Based on our results, the literature on psychotherapy research seems to be particularly sensitive to this issue.

The fourth research topic identified in our results was psychopathology. Papers within this cluster dealt mainly with prevalence and risk factors especially of mood disorders, suicide behavior, and substance abuse, mostly but not exclusively in the adult population. Thus, this topic reflects the interest of current psychotherapy researchers in the investigation of severe psychopathological syndromes from a psychiatric perspective. Such a result is interesting insofar as it suggests, coherently with previous investigations (Gennaro et al., 2012), that psychotherapy research focuses not only on the investigation of different aspects of psychotherapeutic treatments and forms of intervention (see the research topics discussed above; Lambert, 2013a, 2013b), but also on the investigation of the disorders themselves which are the subject of clinical interventions. This result, which might appear relatively surprising to at least some of the scholars who are generally familiar with an idea of psychotherapy research as a discipline mainly concerned with the treatment of mental suffering (rather than with mental suffering itself), indicates that psychopathology represents a topic for psychotherapy research insofar as it is considered from a psychiatric perspective. Indeed, this result can be explained considering the presence in our sample of two psychiatric journals (out of a total of 10 journals) which, together, account for almost $40 \%$ of the total number of papers analyzed (Table 1; see below for a discussion).

Finally, we identified the research topic neuroscientific approaches to mental disorders, dealing with papers focusing on neurobiological correlates of different mental disorders mainly - though not exclusively - investigated by means of neuroimaging techniques. This research topic is related to the research topic psychopathology just discussed above, nevertheless in this cluster the mental disorders are investigated and explained with reference to their neurobiological substrates and/or impairments. This result can be explained considering the extremely high rates of papers published by the two psychiatric journals included in our sample (see below for a discussion). Interestingly, this cluster does not include studies aimed at investigating the neural correlates of treatment response and, even less, treatment mediators, which are considered by many psychotherapy researchers to allow a better understanding of how psychotherapeutic interventions achieve their efficacy (Caspar, 2015; Weingarten \& Strauman, 2015).Thus, it would seem that, in the field of psy- chotherapy research, the neuroscientific approaches are still a prerogative of a psychiatric approach to psychopathology, and a lot still has to be done in order to employ such a paradigm within outcome, process, and process-outcome research.

\section{Trend over time}

With regard to our second research question, our results showed that these different research topics present a different trend over the time-frame considered (20002016), with the two most frequent research topics (clinical relationship and clinical efficacy) increasing over time, and the other three (clinical practice and research, psychopathology, and neuroscientific approaches to mental disorders) decreasing (Table 3). The increase in the first two research topics seems to be indicative of a growing commitment of psychotherapy researchers toward an evidence-based psychotherapeutic practice, where the effort is concentrated on identifying the technical (ESTs) and relational (ESRs) treatment elements through which therapy works (Chambless \& Hollon, 1998; Norcross, 2011). Based on this, we might say that "the call for evidencebased practice is increasingly influencing psychotherapy" (Gaudiano \& Miller, 2013; p. 814).

Interestingly, the increased attention to the first two research topics was paralleled by a decreased interest in the topic of clinical practice and research. Thus, it might seem that psychotherapy researchers, while increasingly embracing an EBP paradigm, are slowly pushing a more general reflection and discussion on different aspects of professional practice and training and of research-practice bridging into the background. If this were to be the case, we would not see it favorably. Indeed, while we do believe in the potential of an EBP approach, we also believe that a critical reflection on it, together with the constant effort to question and possibly further articulate it, should be a primary aim of psychotherapy research (for a review and discussion on critical thinking as disciplinary practice, see Yanchar, Slife, \& Warne, 2008; see also Gelo et al., 2019).

Finally, the falling number of publications concerning the research topics of psychopathology and neuroscientific approaches to mental disorders might be indicative of the fact the such an approach is slowly losing ground in the field of psychotherapy research.

\section{Distribution among journals}

Finally, concerning the third research question, our results showed a different distribution of the research topics among the journals considered. First of all, it should be observed that the topics of clinical relationship, clinical efficacy, and clinical practice and research are mostly published by the eight non-psychiatric journals of our sample, while the topics of psychopathology and neuroscientific approaches to mental disorders by the remaining two psychiatric journals (Table 4). This last result is co- 
herent with the psychiatric orientation of the two latter topics, which has been discussed above. Based on this, it might be said that the topics of psychotherapy research, together with the journals publishing them, can be distinguished in having a non-psychiatric (i.e., more strictly psychotherapeutic) vs psychiatric orientation. Interesting to observe, Behavior Therapy was the only school-specific journal present in our sample based on the indications of the ex SPR-presidents, thus indicating how relevant empirical research is for cognitive-behavioral psychotherapy compared to other specific therapeutic approaches.

Second, the research topic clinical relationship was associated with five (out of 10) journals in our sample, while each other research topic was associated only with two journals (Table 4). Thus, in this regard, clinical relationship is the most widespread topic among the different journals examined - followed equally by the other topics - coherently with the relational orientation of current psychotherapy research already discussed above.

A final observation can be made by taking into account the Impact Factor (IF) of the different journals. The journals with the highest IF (12.84 for Archives of General Psychiatry and 10.41 for American Journal of Psychiatry) mostly publish the topics of psychopathology and neuroscientific approaches to mental disorders. These are followed by a journal with the third highest IF ( 4.45 for Journal of Consulting and Clinical Psychology), which is associated with the topic of clinical efficacy. Finally, we have the remaining journals, whose IF ranges between 2.30 and 1.04, publishing the topics of clinical efficacy, clinical relationship, and clinical practice and research. Thus, it would seem that the psychiatric-oriented topics are the most cited and widespread, followed by clinical efficacy and, to finish with, clinical relationship, and clinical practice and research. Such a result can be useful for scholars deciding where to submit their papers, showing that journals with an extremely high or very high IF are actually dedicated mostly to a narrow set of topics: psychopathology and neuroscientific approaches to mental disorders for the two psychiatric-oriented journals (Archives of General Psychiatry and American Journal of Psychiatry) and clinical efficacy for the best IF-ranked non-psychiatric-oriented journal (Journal of Consulting and Clinical Psychology). By contrast, if scholars are willing to publish papers dealing with clinical relationship and/or clinical practice and research, they should opt for journals with a lower IF.

\section{Limitations and future studies}

The present study presents some limitations. First, we analyzed only the first 10 journals obtained by the ranked list of all the journals that the SPR past-presidents identified as the most representative in the field. Future studies should enlarge the sample to the whole set of journals identified by them. Second, the sample of journals inves- tigated is necessarily biased by the choice made by SPR past-presidents - and thus, by their scientific and cultural milieu. Although we do believe that such a choice may be quite authoritative - considering that SPR is actually the biggest society devoted to the investigation of psychotherapy - we cannot ignore the fact that this may have influenced our findings. Future studies should broaden the criteria used to identify target journals, for example by means of a survey asking practitioners which are, in their view, the most representative psychotherapy research journals. Third, the selected time-frame (2000-2016), though relatively broad - especially for this kind of systematic reviews - might be broadened, in order to offer an even more representative picture of the topics of psychotherapy research, their temporal trend, and their association with the journals. Fourth, future studies might attempt to map the semantic relation between the clusters, in order to provide a deeper understanding of the semantic landscape of the psychotherapy research field. Fifth, future research might apply the methodology used in the present study within single journals, in order to identify, to a higher degree of specificity, the topic characteristics for the chosen journal.

\section{Conclusions}

The present study aimed at systematically reviewing the literature on psychotherapy research by means of an innovative procedure of computer-assisted bottom-up content analysis, trying to answer the question What does psychotherapy research deal with? In the context of the journal sample and time-frame selected, it was possible to identify the main topics psychotherapy research is currently concerned with, their temporal trend, and their association with the publishing journals. From a theoretical perspective, our findings provide food for thought about what psychotherapy researchers are mainly concerned with, which may be helpful for a meta-theoretical reflection on the current position of the discipline and where it is heading. From a more pragmatic perspective, the map of the journals' thematic orientation may be helpful in orienting scholars when deciding to submit their papers. With this regard, it has to be underlined that the such a map must not be intended as an objective, detailed representation of the ever-changing scenario of psychotherapy research. Rather, it has to be seen as an interpretative device useful for deepening the understanding of the current status of research in the field (Gennaro et al., 2012). Finally, from a methodological perspective, our findings show the utility of adopting quali-quantitative method of content analysis, where multidimensional techniques of data analysis ground and support the researcher's interpretative task, rather than replacing it, as tools to provide a meaningful picture of a scenario as complex as psychotherapy research (Salvatore et al., 2017, 2012). A picture, moreover, that already at the current level of 
definition may provide hints about the Journals' scientificcultural policies - a rather important issue with pragmatic implications at the institutional and individual level.

\section{Acknowledgements}

We would like to thank the following SPR past presidents who replied to our survey: Lynne Angus, Lorna Smith Benjamin, Larry E. Beutler, Louis G. Castonguay, John Clarkin, Paul Crits-Christoph, Guillermo de la Parra, Irene Elkin, Robert Elliot, Marvin R. Goldfried, Leslie S. Greenberg, Alan S. Gurman, Clara E. Hill, Mardi J. Horowitz, Horst Kächele, Michael J. Lambert, Erhard Mergenthaler, David E. Orlinksy, William E. Piper, George Silberschatz, William B. Stiles, Bernhard Strauß, Jeanne Watson, Hadas Wiseman.

\section{References}

Aldenderfer, M., \& Blashfield, R. (1984). Cluster Analysis. London, UK: SAGE Publications.

American Psychological Association, Presidential Task Force on Evidence-Based Practice (2006). Evidence-based practice in psychology. American Psychologist, 61(4), 271-285. doi: 10.1037/0003-066X.61.4.271

Blake, G., \& Bly, R. W. (1993). The elements of technical writing. New York, NY: Macmillan.

Boisvert, C. M., \& Faust, D. (2006). Practicing psychologists' knowledge of general psychotherapy research findings: Implications for science-practice relations. Professional Psychology: Research and Practice, 37(6), 708-716. doi: 10.1037/0735-7028.37.6.708

Borkenhagen, A. (2002). Bibliometric analysis: the journal of the Society for Psychotherapy Research and the diversity of psychotherapy research: A compilation and comparison of North American and European contributions. Psychotherapy Research, 12(4), 491-514. doi: 10.1093/ptr/12.4.491

Braakmann, D. (2015). Historical Paths in Psychotherapy Research. In O. C. G Gelo, A. Pritz, \& B. Rieken (Eds.), Psychotherapy research: Foundations, process, and outcome (pp. 39-65). Vienna: Springer.

Buboltz, W., Deemer, E., \& Hoffmann, R. (2010). Content analysis of the Journal of Counseling Psychology: Buboltz, Miller, and Williams (1999) 11 years later. Journal of Counseling Psychology, 57(3), 368-375. doi: 10.1037/a0020028

Buboltz, W. C. J., Miller, M., \& Williams, D. J. (1999). Content analysis of research in the Journal of Counseling Psychology (1973-1998). Journal of Counseling Psychology, 46(4), 496-503. doi: 10.1037//0022-0167.46.4.496

Bucci, W., \& Maskit, B. (2006). A weighted dictionary for Referential Activity. In J. G. Shanahan, Y. Qu, \& J. Wiebe (Eds.), Computing attitude and affect in text (pp. 49-60). Dordrecht: Springer.

Budge, S. L., \& Wampold, B. E. (2015). The relationship: how it works. In O. C. G. Gelo, A. Pritz, \& B. Rieken (Eds.), Psychotherapy Research: Foundations, process, and outcome (pp. 213-228). Vienna: Springer.

Caspar, F. (2015). Psychotherapy research and neurobiology: Challenge, chance, or enrichment? Are we wiser 10 years later? In B. M. Strauss, J. P. Barber, \& L. G. Castonguay (Eds.), Visions in psychotherapy research and practice (pp. 209-230). New York, NY: Routledge.

Chambless, D. L., \& Hollon, S. D. (1998). Defining empirically supported therapies. Journal of Consulting and Clinical Psychology, 66(1), 7-18. doi: 10.1037/0022-006X.66.1.7

Chung, C. K., \& Pennebaker, J. W. (2008). Variations in the spacing of expressive writing sessions. British Journal of Health Psychology, 13(1), 15-21. doi: 10.1348/135910707X251171

Daniel, S. I. F. (2006). Adult attachment patterns and individual psychotherapy: A review. Clinical Psychology Review, 26(8), 968-984. doi: 10.1016/j.cpr.2006.02.001

Eysenck, H. J. (1952). The effects of psychotherapy: An evaluation. Journal of Consulting Psychology, 16(5), 319-324. doi: $10.1037 / \mathrm{h} 0063633$

Flückiger, C., Del Re, A. C., Wampold, B. E., Symonds, D., \& Horvath, A. O. (2012). How central is the alliance in psychotherapy? A multilevel longitudinal meta-analysis. Journal of Counseling Psychology, 59(1), 10-17. doi: 10.1037/a0025749

Gaudiano, B. A., \& Miller, I. W. (2013). The evidence-based practice of psychotherapy: Facing the challenges that lie ahead. Clinical Psychology Review, 33(7), 813-824. doi: 10.1016/j.cpr.2013.04.004

Gelo, O. C. G., Lagetto, G., Dinoi, C., Belfiore, E., Lombi, E., Blasi, S., ... Ciavolino, E. (2019a). Correction to: Which methodological practice(s) for psychotherapy science? A systematic review and a proposal. Integrative Psychological and Behavioral Science. https://doi.org/10.1007/s12124019-09502-6

Gelo, O. C. G., Pritz, A., \& Rieken, B. (Eds.). (2015). Psychotherapy Research: Foundations, Process and Outcome. Vienna: Springer.

Gennaro, A., Venuleo, C., Auletta, A. F., \& Salvatore, S. (2012). The topics of psychotherapy research: An analysis based on keywords. Research in Psychotherapy: Psychopathology, Process and Outcome, 15(1), 1-9. doi: 10.4081/ripppo. 2012.117

Grant, M. J., \& Booth, A. (2009). A typology of reviews: An analysis of 14 review types and associated methodologies. Health Information \& Libraries Journal, 26(2), 91-108. doi: 10.1111/j.1471-1842.2009.00848.x

Green, D., \& Latchford, G. (2012). Maximising the benefits of psychotherapy: A practice-based evidence approach. Chichester, UK: Wiley.

Hill, C. E., \& Knox, S. (2013). Training and supervision in psychotherapy. In M. J. Lambert (Ed.), Bergin and Garfield's handbook of psychotherapy and behavior change (pp. 775812). New York, NY: Wiley.

Hill, C. E., Nutt, E. A., \& Jackson, S. (1994). Trends in psychotherapy process research: Samples, measures, researchers, and classic publications. Journal of Counseling Psychology, 41(3), 364-377. doi: 10.1037//00220167.41.3.364

Hill, C. E, Thompson, B. J., Hess, S. A., Knox, S., Williams, E. N., \& Ladany, N. (2005). Consensual qualitative research: An update. Journal of Counseling Psychology, 52(2), 196205. doi: 10.1037/0022-0167.52.2.196

Hofmann, S. G., Wu, J. Q., \& Boettcher, H. (2014). Effect of cognitive-behavioral therapy for anxiety disorders on quality of life: A meta-analysis. Journal of Consulting and Clinical Psychology, 82(3), 375-391. doi: 10.1037/a0035491

Hopewell, S. (2008). CONSORT for reporting randomized con- 
trolled trials in journal and conference abstracts: explanation and elaboration. Journal of Chinese Integrative Medicine, 6(3), 221-232. doi: 10.3736/jcim20080301

Kazantzis, N., Cronin, T. J., Norton, P. J., Lai, J., \& Hofmann, S. G. (2015). Reservations about the conclusions of the Interdivisional (APA Divisions 12 \& 29) Task Force on Evidence-Based Therapy Relationships: What do we know, what don't we know? Journal of Clinical Psychology, 71(5), 423-427. doi: 10.1002/jclp.22178

Lambert, M. J. (2013a). Introduction and historical overview. In M. J. Lambert (Ed.), Bergin and Garfield's handbook of psychotherapy and behavior change (6th ed., pp. 3-20). Hoboken, NJ: Wiley.

Lambert, M. J. (2013b). The efficacy and effectiveness of psychotherapy. In M. J. Lambert (Ed.), Bergin and Garfield's handbook of psychotherapy and behavior change (6th ed., pp. 169-218). Hoboken, NJ: Wiley.

Lancia, F. (2004). Strumenti per l'analisi dei testi. Introduzione all'uso di T-Lab. [Tools for text analysis. An introduction to the use of T-Lab.]. Milan, Italy: Franco Angeli.

Landauer, T. K., \& Dumais, S. T. (1997). A solution to Plato's problem: The latent semantic analysis theory of acquisition, induction, and representation of knowledge. Psychological Review, 104(2), 211-240. doi: 10.1037/0033-295X.104. 2.211

Leichsenring, F. (2004). Randomized controlled versus naturalistic studies: A new research agenda. Bulletin of the Menninger Clinic, 68(2), 137-151. doi: 10.1521/bumc.68.2.137. 35952

Lilienfeld, S. O., Ritschel, L. A., Lynn, S. J., Cautin, R. L., \& Latzman, R. D. (2013). Why many clinical psychologists are resistant to evidence-based practice: Root causes and constructive remedies. Clinical Psychology Review, 33(7), 883-900. doi: 10.1016/j.cpr.2012.09.008

Lingiardi, V., Holmqvist, R., \& Safran, J. D. (2016). Relational turn and psychotherapy research. Contemporary Psychoanalysis, 52(2), 275-312. doi: 10.1080/00107530.2015. 1137177

Manzo, S. (2010). La ricerca di processo nel decennio 19982007: Contributo a una review critica [Process research in the decade 1998-2007: Contribution to a critical review]. Research in Psychotherapy: Psychopathology, Process and Outcome, 13(1), 92. doi: 10.4081/ripppo.2010.11

Max, R. (1993). Les mondes lexicaux et leur logique à travers l'analyse statistique d'un corpus de récits de cauchemars [Lexical worlds and their logic through the statistical analysis of a body of stories of nightmares]. Langage et Société, 66(1), 5-39. doi: 10.3406/lsoc.1993.2632

McAleavey, A. A., \& Castonguay, L. G. (2015). The process of change in psychotherapy: Common and unique factors. In O. C. G. Gelo, A. Pritz, \& B. Rieken (Eds.), Psychotherapy research: Foundations, process, and outcome (pp. 293310). Vienna: Springer.

Mergenthaler, E. (1996). Emotion-abstraction patterns in verbatim protocols: A new way of describing psychotherapeutic processes. Journal of Consulting and Clinical Psychology, 64(6), 1306-1315. doi: 10.1037//0022-006X.64.6.1306

Moher, D., Liberati, A., Tetzlaff, J., \& Altman, D. G. (2009). Preferred reporting items for systematic reviews and metaanalyses: The PRISMA statement. PLoS Medicine, 6(7), e1000097. doi: 10.1371/journal.pmed.1000097

Mörtl, K., \& Gelo, O. C. G. (2015). Qualitative methods in psychotherapy process research. In O. C. G. Gelo, A. Pritz, \& B. Rieken (Eds.), Psychotherapy research: Foundations, process, and outcome (pp. 381-428). Vienna: Springer.

Munley, P. H. (1974). A content analysis of the Journal of Counseling Psychology. Journal of Counseling Psychology, 21(4), 305-310. doi: 10.1037/h0036659

Newnham, E. A., \& Page, A. C. (2010). Bridging the gap between best evidence and best practice in mental health. Clinical Psychology Review, 30(1), 127-142. doi: 10.1016/j.cpr. 2009.10.004

Norcross, J. C. (Ed.). (2011). Psychotherapy relationships that work: Evidence-based responsiveness ( $2 \mathrm{nd}$ ed.). New York, NY: Oxford University Press.

Phillips, J. C., Ingram, K. M., Smith, N. G., \& Mindes, E. J. (2003). Methodological and content review of lesbian-, gay, and bisexual-related articles in counseling journals: 19901999. The Counseling Psychologist, 31(1), 25-62. doi: 10.1177/0011000002239398

Pitkin, R. M., \& Branagan, M. A. (1998). Can the accuracy of abstracts be improved by providing specific instructions? JAMA, 280(3), 267. doi: 10.1001/jama.280.3.267

Reinert M. (1993). Les 'mondes lexicaux' et leur 'logique' à travers l'analyse statistique d'un corpus de récits de cauchemars, Langage et Société, 66.

Rønnestad, M. H., Orlinsky, D. E., Schröder, T. A., Skovholt, T. M., \& Willutzki, U. (2018). The professional development of counsellors and psychotherapists: Implications of empirical studies for supervision, training and practice. Counselling and Psychotherapy Research. doi: 10.1002/capr. 12198

Roth, A., \& Fonagy, P. (2005). What works for whom? A critical review of psychotherapy research (2nd ed.). New York, NY: Guilford Press.

Safran, J. D., Abreu, I., Ogilvie, J., \& DeMaria, A. (2011). Does psychotherapy research influence the clinical practice of researcher-clinicians? Clinical Psychology: Science and Practice, 18(4), 357-371. doi: 10.1111/j.1468-2850.2011. 01267.x

Salvatore, S., Gennaro, A., Auletta, A., Grassi, R., Manzo, S., Nitti, M., Al-Radaideh, A., Tonti, M., Aloia, N., Monteforte, G. \& Gelo, O. (2010). La psicoterapia come scambio comunicativo. Prospettive di ricerca sul processo clinico. In Research in Psychotherapy: Psychopathology, Process and Outcome 2(13): 241-286.

Salvatore, S., Gelo, O. C. ., Gennaro, A., Metrangolo, R., Terrone, G., Pace, V., ... Ciavolino, E. (2017). An automated method of content analysis for psychotherapy research: A further validation. Psychotherapy Research, 27(1), 38-50. doi: 10.1080/10503307.2015.1072282

Salvatore, S., Gennaro, A., Auletta, A. F., Tonti, M., \& Nitti, M. (2012). Automated method of content analysis: A device for psychotherapy process research. Psychotherapy Research, 22(3), 256-273. doi: 10.1080/10503307.2011.647930

Singh, A. A., \& Shelton, K. (2011). A content analysis of LGBTQ qualitative research in Counseling: A ten-year review. Journal of Counseling \& Development, 89(2), 217226. doi: 10.1002/j.1556-6678.2011.tb00080.x

Slife, B. D., \& Wiggins, B. J. (2009). Taking relationship seriously in psychotherapy: Radical relationality. Journal of Contemporary Psychotherapy, 39(1), 17-24. doi: 10.1007/ s10879-008-9100-6

Slife, B. D., Wiggins, B. J., \& Graham, J. T. (2005). Avoiding an EST monopoly: Toward a pluralism of philosophies and methods. Journal of Contemporary Psychotherapy, 35(1), 83-97. doi: 10.1007/s10879-005-0805-5 
Stewart, A. E., Stewart, E. A., \& Gazda, G. M. (1997). Assessing the need for a new group journal. Group Dynamics: Theory, Research, and Practice, 1(1), 75-85. doi: 10.1037//10892699.1.1.75

Stewart, R. E., Stirman, S. W., \& Chambless, D. L. (2012). A qualitative investigation of practicing psychologists' attitudes toward research-informed practice: Implications for dissemination strategies. Professional Psychology: Research and Practice, 43(2), 100-109. doi: 10.1037/a0025694

Stiles, W. B., Hurst, R. M., Nelson-Gray, R., Hill, C. E., Greenberg, L. S., Watson, J. C., ... Hollon, S. D. (2006). What qualifies as research on which to judge effective practice? In J. C. Norcross, L. E. Beutler, \& R. F. Levant (Eds.), Evidence-based practices in mental health: Debate and dialogue on the fundamental questions (pp. 56-130). Washington, DC, US: American Psychological Association.

Tausczik, Y. R., \& Pennebaker, J. W. (2010). The psychological meaning of words: LIWC and computerized text analysis methods. Journal of Language and Social Psychology, 29(1), 24-54. doi: 10.1177/0261927X09351676

Wachtel, P. (2008). Relational theory and the practice of psychotherapy. New York, NY: Guilford Press.
Wampold, B. E., \& Imel, Z. E. (2015). The great psychotherapy debate: The evidence for what makes psychotherapy work (2nd ed.). New York, NY: Routledge.

Weingarten, C. P., \& Strauman, T. J. (2015). Neuroimaging for psychotherapy research: Current trends. Psychotherapy Research, 25(2), 185-213. doi: 10.1080/10503307.2014. 883088

Wolf, M., Chung, C. K., \& Kordy, H. (2010). Inpatient treatment to online aftercare: E-mailing themes as a function of therapeutic outcomes. Psychotherapy Research, 20(1), 71-85. doi: 10.1080/10503300903179799

Yanchar, S. C., Slife, B. D., \& Warne, R. (2008). Critical thinking as disciplinary practice. Review of General Psychology, 12(3), 265-281. doi: 10.1037/1089-2680.12.3.265

Yavchitz, A., Boutron, I., Bafeta, A., Marroun, I., Charles, P., Mantz, J., \& Ravaud, P. (2012). Misrepresentation of randomized controlled trials in press releases and news coverage: A cohort study. PLoS Medicine, 9(9), e1001308. doi: 10.1371/journal.pmed.1001308

Yoon, E., Langrehr, K., \& Ong, L. Z. (2011). Content analysis of acculturation research in counseling and counseling psychology: A 22-year review. Journal of Counseling Psychology, 58(1), 83-96. doi: 10.1037/a0021128 